\title{
The penetration of chromium-EDTA from blood plasma into various compartments of rat testes as an indicator of function of the blood-testis barrier after exposure of the testes to heat
}

\author{
B. P. Setchell, L. Tao and J. L. Zupp \\ Department of Animal Science, University of Adelaide (Waite), Adelaide, South Australia 5064, Australia
}

\begin{abstract}
The concentration of chromium ${ }^{51}$-EDTA in blood plasma after an intravenous infusion was found to be about 40 times that present in rete testis fluid and 20 times that in the additional seminiferous tubular fluid resulting from ligation of the efferent ducts. These values indicate the effectiveness of the blood-testis barrier to small water-soluble molecules, like Cr-EDTA. The volume of distribution in microlitres of $\mathrm{Cr}$-EDTA in the parenchyma was about $60 \%$ of the volume of the interstitial tissue as determined on frozen sections by morphometry, and was similar, or slightly less, in the ligated testes, compared with the unligated testes. Heating the testes to $43^{\circ} \mathrm{C}$ for $30 \mathrm{~min}$ led to the expected reduction several days later in testis mass, but the volume of distribution of $\mathrm{Cr}$-EDTA was no greater than that in the testes of control rats, and the ratio of $\mathrm{Cr}$-EDTA space to interstitial tissue was not different, while the concentration of $\mathrm{Cr}-\mathrm{EDTA}$ in the additional seminiferous tubular fluid increased only slightly as testis mass fell. These results indicate that the blood-testis barrier was only slightly less effective, if changed at all, during the period of spermatogenic disruption following local heating of the testis.
\end{abstract}

\section{Introduction}

The blood-testis barrier maintains a unique fluid environment surrounding the developing germ cells. The existence of the barrier has been demonstrated functionally by the differences in composition between the fluid in the lumen of the semiferous tubule and blood plasma and testicular lymph, and from studies involving measurements of the rate of movement of various marker substances from blood plasma into luminal or rete testis fluid (see Setchell et al. 1994 for recent review). Substances such as chromium-EDTA (Cr-EDTA), sucrose and inulin, which are used as markers for extracellular fluid, are virtually excluded from rete testis fluid in rams (Setchell et al., 1969), and the volume of distribution of sucrose and inulin are similar in control testes and in testes in which the tubular fluid secreted in the previous $16 \mathrm{~h}$ has been trapped inside the seminiferous tubules by ligation of the efferent ducts (Setchell, 1974). The barrier develops around the time of puberty (Setchell et al., 1988). In mink, the barrier becomes less effective outside the breeding season (Pelletier, 1986, 1988).

It has been known for some time that exposure of scrotal testes to temperatures similar to, or greater than, body core temperature leads to disruption of spermatogenesis, and a single, quite short, period of exposure between 15 and $30 \mathrm{~min}$, to temperatures of about $43^{\circ} \mathrm{C}$ is sufficient to cause virtual cessation of sperm release 7-35 days later (Setchell and Waites, 1972). The more mature germ cells seem to be relatively resistant, as are the spermatogonia, and the latter re-establish

Received 28 June 1995. spermatogenesis after an interval determined by the kinetics of spermatogenesis (Steinberger and Dixon, 1959; Choudhury and Steinberger, 1964, 1970; Collins and Lacy, 1969; Jegou et al., 1984; Galil and Setchell, 1988). However, the mechanism of the effect of heat is not known, nor is it clear whether the blood-testis barrier remains intact during the disruption to spermatogenesis. It was, therefore, of interest to measure the effectiveness of the barrier in the testes of rats following a single exposure of the testes to heat.

\section{Materials and Methods}

\section{Experiment 1}

This experiment was conducted while one of the authors (B. P. Setchell) was working at the Institute of Animal Physiology, Babraham, Cambridge. Nine adult, Wistar strain, rats $349 \pm 10.3 \mathrm{~g}$ were anaesthetized with sodium pentobarbitone $\left(50 \mathrm{mg} \mathrm{kg}^{-1}\right.$ body mass i.p.) and the efferent ducts of one testis ligated near the testis, as described by Setchell (1970). Twenty hours later, the rats were anaesthetized again, using the same dose of anaesthetic. One jugular vein was cannulated and ${ }^{51} \mathrm{Cr}$-EDTA (Amersham International, Amersham, Bucks; $0.1 \mathrm{ml} \mathrm{min}{ }^{-1}$ of a solution containing $4 \mu \mathrm{Ci} \mathrm{ml}{ }^{-1}$ ) was infused for $30 \mathrm{~min}$. At the end of this time, with the infusion continuing, rete testis fluid was collected from the ligated testis by the technique described by Setchell and Main (1975), and samples of blood were taken from a testicular vein on the surface of the unligated testis and from the posterior vena cava. 
Both testes were removed, weighed and decapsulated and the parenchyma forced through a 21 gauge needle, using a $5 \mathrm{ml}$ syringe, as described by Setchell et al. (1976); the cell dispersion was centrifuged at $10000 \mathrm{~g}$ for $10 \mathrm{~min}$, yielding a sediment of cells and an opalescent supernatant fluid. The cells and fluid were separated, weighed and the radioactivity in them and in measured volumes of plasma and rete testis fluid was counted with a gamma spectrometer. The samples of rete testis fluid were also analysed for sodium and potassium by flame photometry, as described by Setchell ef al. (1971). Volumes of distribution or 'spaces' in $\mu \mathrm{l}$ or $\mu \mathrm{l} \mathrm{g}^{-1}$ were calculated by dividing c.p.m. per sample or c.p.m. $\mathrm{g}^{-1}$ tissue or fluid by c.p.m. $\mu \mathrm{I}^{-1}$ plasma. Values for the parenchyma were obtained by adding the mass and the amount of radioactivity in the cell and fluid fractions from that testis. The concentration of radioactivity in the additional seminiferous tubular fluid trapped in the testis by the efferent duct ligature was calculated as described by Setchell et al. (1976), that is, (radioactivity in supernatant fluid from ligated testis - radioactivity in fluid from unligated testis)/(mass of supernatant fluid from ligated testis - mass of fluid from unligated testis).

\section{Experiment 2}

Porton strain rats, bred at the University of Adelaide Central Animal House were used in all the other experiments. Twentyfive adult rats $(403 \pm 7.5 \mathrm{~g})$ were anaesthetized with sodium pentobarbitone. The testes of 10 rats were heated by immersing the scrotum for $30 \mathrm{~min}$ in a water bath maintained at $43^{\circ} \mathrm{C}$, as described by Galil and Setchell (1988). Fifteen control rats were anaesthetized in the same way, but the scrotum was immersed in a water bath at $33^{\circ} \mathrm{C}$, the normal scrotal temperature in this species. Twenty-one days later, all rats were subjected to unilateral efferent duct ligation, as in Expt 1. In 14 of the rats (eight control and six heated), an i.v. injection of ${ }^{125}$ I-iodinated human serum albumin (Amersham, $1 \mu \mathrm{Ci}$ in $0.2 \mathrm{ml}$ saline) was given into one jugular vein at the time of ligation and in the remaining rats, a jugular infusion of Cr-EDTA was started about $20 \mathrm{~h}$ after ligation, as in Expt 1 , but for $10 \mathrm{~min}$ in four control animals and for $20 \mathrm{~min}$ in the remaining animals, after a priming dose of $3 \mu \mathrm{Ci}$ in $0.3 \mathrm{ml}$ saline. Blood samples were removed from the posterior vena cava, from a testicular vein on the unligated testis in the rats infused with Cr-EDTA and from both testicular veins in the rats injected with iodinated albumin. The testes were removed and processed as in Expt 1, except that rete testis fluid was not collected. In 17 similar rats, blood samples were removed from a catheter in one femoral artery for estimation of radioactivity at 2, 5, 10, 15 and 20 min during an i.v. infusion of $\mathrm{Cr}-\mathrm{EDTA}$ after a priming dose as described above. For the calculation of the volume of distribution for $\mathrm{Cr}-\mathrm{EDTA}$, the final plasma concentration was used, but for iodinated albumin, the mean concentration of the marker in blood plasma was calculated by multiplying the final concentration by 1.82 , the ratio of the mean concentration during the period between injection of the marker and sampling at $20 \mathrm{~h}$ and the final concentration at that time; this was determined by analysing a series of blood samples collected at various times after a single i.v. injection of the marker into a group of 20 similar rats (Setchell, 1990).

\section{Experiment 3}

Forty-one adult rats similar to those used in Expt 2, weighing $346 \pm 7.7 \mathrm{~g}$ were used. The testes of 32 rats were heated, with nine serving as controls as described in Expt 2. At various times after the heating, groups of one control and four heated rats were anaesthetized again, the efferent ducts of one testis ligated, and $20 \mathrm{~h}$ later, blood and testes collected at the end of an i.v. infusion following a priming dose of $\mathrm{Cr}$-EDTA, as in Expt 2. In the group receiving the Cr-EDTA infusion 63 days after the heating, two of the treatment rats died during the infusion. Spaces were calculated from the final plasma concentrations.

\section{Experiment 4}

Sixty adult rats, similar to those used earlier, weighing $534 \pm 9.9 \mathrm{~g}$ were used. The testes of 30 of the rats were heated in a water bath at $43^{\circ} \mathrm{C}$ for $30 \mathrm{~min}$, with the testes of the other half immersed in a bath at $33^{\circ} \mathrm{C}$ as controls, and similar numbers of the two groups were examined at various times after heating. One heated and one control in the group examined 2 days after the heating and one control rat in the group examined 14 days after the heating died during the infusion. Instead of a priming dose and constant infusion, an electronically controlled syringe pump (see Pratt 1974; Daniel et al., 1975) was used to give a priming dose of $3 \mu \mathrm{Ci}$ in $0.3 \mathrm{ml}$ in $20 \mathrm{~s}$, followed by an exponentially decreasing infusion of $2 \mu \mathrm{Ci}$ in $0.25 \mathrm{ml}$ over $20 \mathrm{~min}$ (a mean of $52 \mu \mathrm{l}$ during the first minute, $32,24,20,15$ and $12 \mu \mathrm{l} \mathrm{min}{ }^{-1}$ during the 2 nd to 6 th

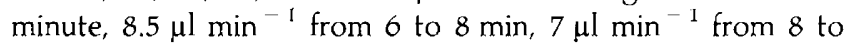
$10 \mathrm{~min}, 6.2 \mu \mathrm{l} \mathrm{min}{ }^{-1}$ from 10 to $15 \mathrm{~min}$ and $5.8 \mu \mathrm{l} \mathrm{\textrm {min } ^ { - 1 }}$ thereafter; this procedure was chosen on the basis of preliminary observations to produce a constant plasma concentration, at least between 10 and $20 \mathrm{~min}$ ). In 24 of the rats, blood samples were collected from the femoral artery after 2, 5, 10, 15 and $20 \mathrm{~min}$; in the remaining rats, a single blood sample was collected from the posterior vena cava after $20 \mathrm{~min}$. Both testes were then removed and weighed, half of each was frozen immediately in liquid nitrogen, and the rest decapsulated and separated into fluid and cells as described above. Spaces were calculated from the mean concentrations of the marker during the infusion, calculated from the multiple blood samples where available or where only a final sample was collected, by multiplying the final concentration by the average mean:final ratio $(1.16 \pm 0.023)$.

At a convenient time afterwards, the frozen testes were cut into slices about $4 \mathrm{~mm}$ thick and sectioned on a cryostat. The box temperature was set between -28 and $-30^{\circ} \mathrm{C}$ and the object temperature between -16 and $-20^{\circ} \mathrm{C}$, according to the hardness of the tissue, with the blade angle at about 7 . Sections, $10 \mu \mathrm{m}$ thick, were cut, transferred to slides treated with $10 \%$ poly-L-lysine solution (Sigma, St Louis, MO), fixed in Clarke's fixative for $2 \mathrm{~min}$, then transferred to $80 \%$ ethanol until they were stained with Weigert and van Gieson stain. The sections were air dried, covered with cover slips and the percentage of interstitial tissue determined using a Leitz microscope connected to a Microbits computer and BQ system IV. A field area of about $2.5 \mathrm{~mm}^{2}$ was drawn, and the tubular area was drawn following the outside of each seminiferous 
tubule section in the field area. One area from each section and three sections from each testis were evaluated.

\section{Statistical analyses}

Results were analysed by unpaired or paired $t$ tests (Statworks), as appropriate in Expts 1 and 2, and by analysis of variance (Super ANOVA) with Duncan's multiple range tests for the main effects and least mean squares for the interactions in Expts 3 and 4, using an Apple Macintosh computer. In Expt 3, the data were pooled for ANOVA into $0,2+4,7+14$, $28+35$ and $49+63$ days after heating, unless otherwise stated, so that the numbers in each group were similar.

\section{Results}

\section{Experiment 1}

The concentration of Cr-EDTA in rete testis fluid at the end of a $30 \mathrm{~min}$ infusion was only $2.6 \%$ of that in plasma, whereas in the additional seminiferous tubular fluid resulting from ligation of the efferent ducts, the concentration was $4.9 \%$ of plasma (Table 1). The concentration of potassium in the samples of rete testes was $14.4 \pm 0.73 \mathrm{mmol} \mathrm{l}^{-1}$ and the concentration of sodium was $143 \pm 2.7 \mathrm{mmol} \mathrm{l}^{-1}$. There was no difference between the concentrations of $\mathrm{Cr}$-EDTA in testicular venous (TV) and posterior vena cava (PVC) blood plasma (TV/PVC $=1.0171 \pm 0.0227, P=0.733$ by paired $t$ test in the nine rats in Table $I$ and 22 other similar rats sampled at about the same time).

The masses of testes, parenchyma and fluid were significantly greater in the ligated testes, whereas there was no difference in the mass of the cell fraction. The volume of distribution or space for Cr-EDTA in the parenchyma was less in the ligated testis, when expressed per gram of tissue, but similar in absolute terms ( $\mu$ l per testis). However, the $\mathrm{Cr}-$ EDTA space in microlitres in the cell fraction was significantly less in the ligated testis, whereas the $\mathrm{Cr}$-EDTA space in the fluid fraction was significantly greater in the ligated testis (Table 1 ).

\section{Experiment 2}

The masses of testes, parenchyma, cells, and fluid were significantly less in the heated testes, and as in Expt 1, the masses of testes, parenchyma and fluid were significantly greater in the ligated testis, although there was no difference in cell masses in the control animals. However, the mass of the cell fraction was significantly greater in the ligated, heated testes than in the corresponding unligated testes $(P=0.013$ for $\mathrm{Cr}$-EDTA and I-albumin animals combined; Table 1).

The Cr-EDTA spaces in parenchyma, cell fraction and fluid from the ligated testes at $10 \mathrm{~min}$ were significantly less than those at $20 \mathrm{~min}$. In the control testes, the values at 10 and 20 min were similar to one another and to the I-albumin spaces in similar testes. The spaces in the parenchyma and cell fraction of the ligated testes were in general less than in the unligated testis, and the spaces in the fluid tended to be greater, especially in the heated testes, although these differences did not all reach statistical significance (probably due to the small numbers of animals used). Both Cr-EDTA and I-albumin spaces in the parenchyma were higher in the heated testes, when expressed per gram of tissue, but were similar, or smaller, in absolute volumes. Likewise the spaces in the cell fraction and the fluid, when expressed in microlitres, were similar or smaller in the heated testes than in controls. In the testicular capsule, the $\mathrm{Cr}$-EDTA space was about $300 \mu \mathrm{g} \mathrm{g}^{-1}$ and the iodinated albumin space was about $250 \mu \mathrm{lg}^{-1}$; neither was affected by any of the treatments (data not shown).

The Cr-EDTA concentration in the additional seminiferous tubular fluid resulting from ligature of the efferent ducts was about $2.2 \%$ of plasma concentrations in the control animals, and about $4.5 \%$ in the heated animals; the corresponding figures for I-albumin were $1.2 \%$ and $5.0 \%$; neither of these differences between heated and control were significant, as the values were quite variable, although the difference for I-albumin approached significance $(P=0.059)$. The amount of fluid secreted by the heated testes, whether measured as the difference in testis mass or the difference in fluid mass between the ligated and unligated testis was not different from controls (Table 1).

With the infusion schedule used in this experiment and in Expt 3, plasma concentrations of $\mathrm{Cr}$-EDTA 2 min after the priming dose were about half those 20 min after the priming dose, and a steady increase was seen during the course of the infusion, so that the mean concentration over $20 \mathrm{~min}$ was $0.675 \pm 0.008$ times the final concentration. There were no significant differences between the concentrations of $\mathrm{Cr}$-EDTA in plasma from the testicular vein (TV) and from the posterior vena cava (PVC) in the $10 \mathrm{~min}$ controls (TV/PVC = $0.886 \pm 0.051)$, the $20 \mathrm{~min}$ controls $(0.967 \pm 0.030)$ or in the heated rats $(0.939 \pm 0.033)$. However, the concentration of iodinated albumin was higher in the testicular vein on the ligated $(\mathrm{L})$ testis than in the posterior vena cava (L TV/PVC = $1.051 \pm 0.0082, P=0.001$ by paired $t$ test) and the testicular vein on the unligated (UL) testis (L TV/UL TV $=1.043 \pm 0.012$, $P=0.016$ by paired $t$ test), which were not different (UL TV/PVC $=1.01 \pm 0.0073$ ).

\section{Experiment 3}

The masses of testes, parenchyma, cells and fluid all fell significantly after heating, with the masses of testes, parenchyma and cells reaching minimum values at 28 days; the fall in fluid mass occurred somewhat later (Table 2). As in the previous experiments, the masses of testes, parenchyma and fluid were significantly greater in the ligated testis, while there was no difference in cell mass in the control animals; again there were differences in cell mass between ligated and unligated testes in the heated animals (significant for combined data for days 7 and 14, days 28 and 35 and days 49 and 63 , $P=0.013,0.007$ and 0.014 , respectively, by paired $t$ test).

The Cr-EDTA spaces in the parenchyma expressed in microlitres per gram were not significantly different between ligated and unligated testes, but increased significantly after heating ( $P=0.0001, \mathrm{~F}=9.905$ by ANOVA). The space in absolute units was slightly, but significantly, higher in the ligated testes $(P=0.002, F=10.315)$, but was unaffected by 


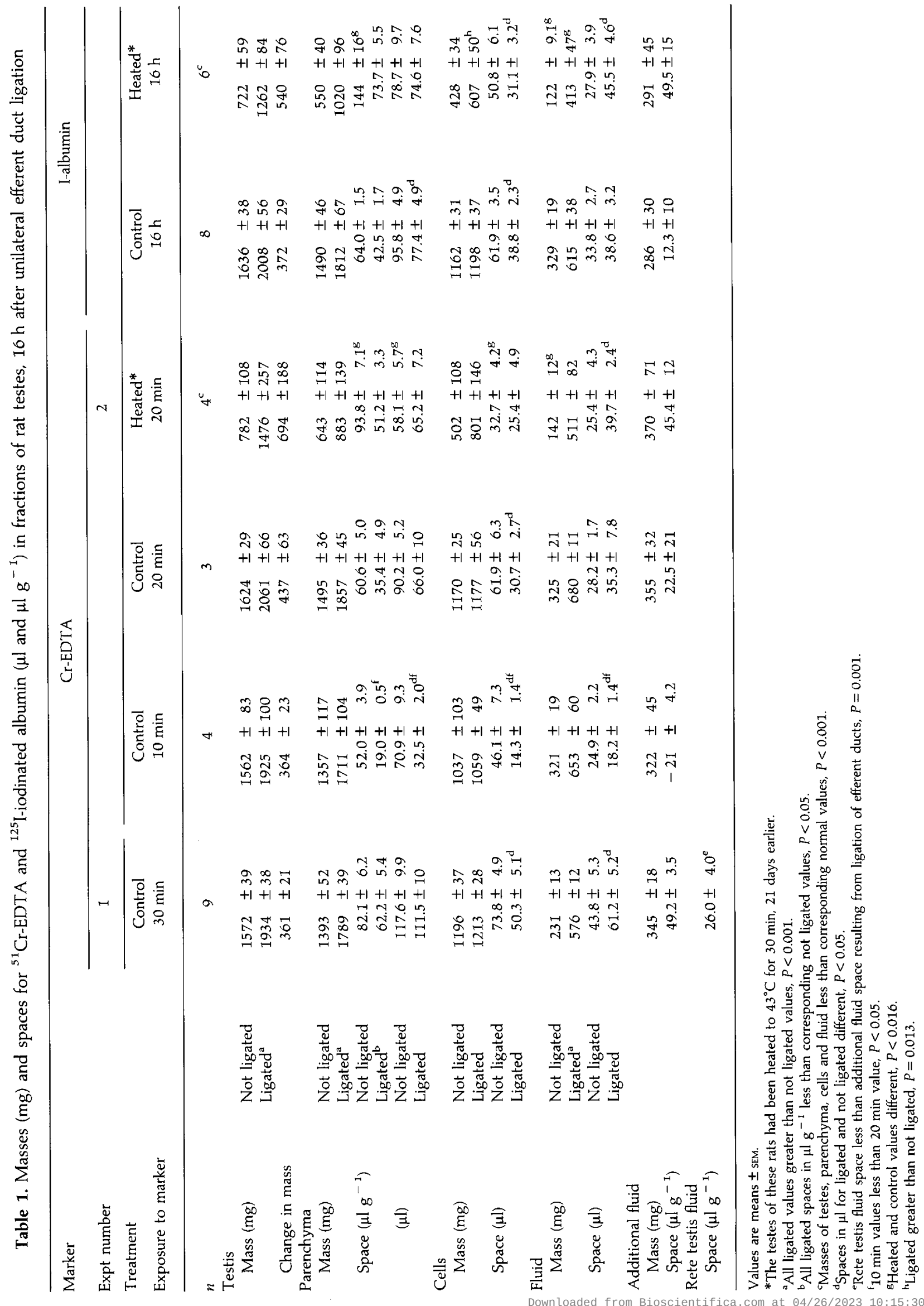




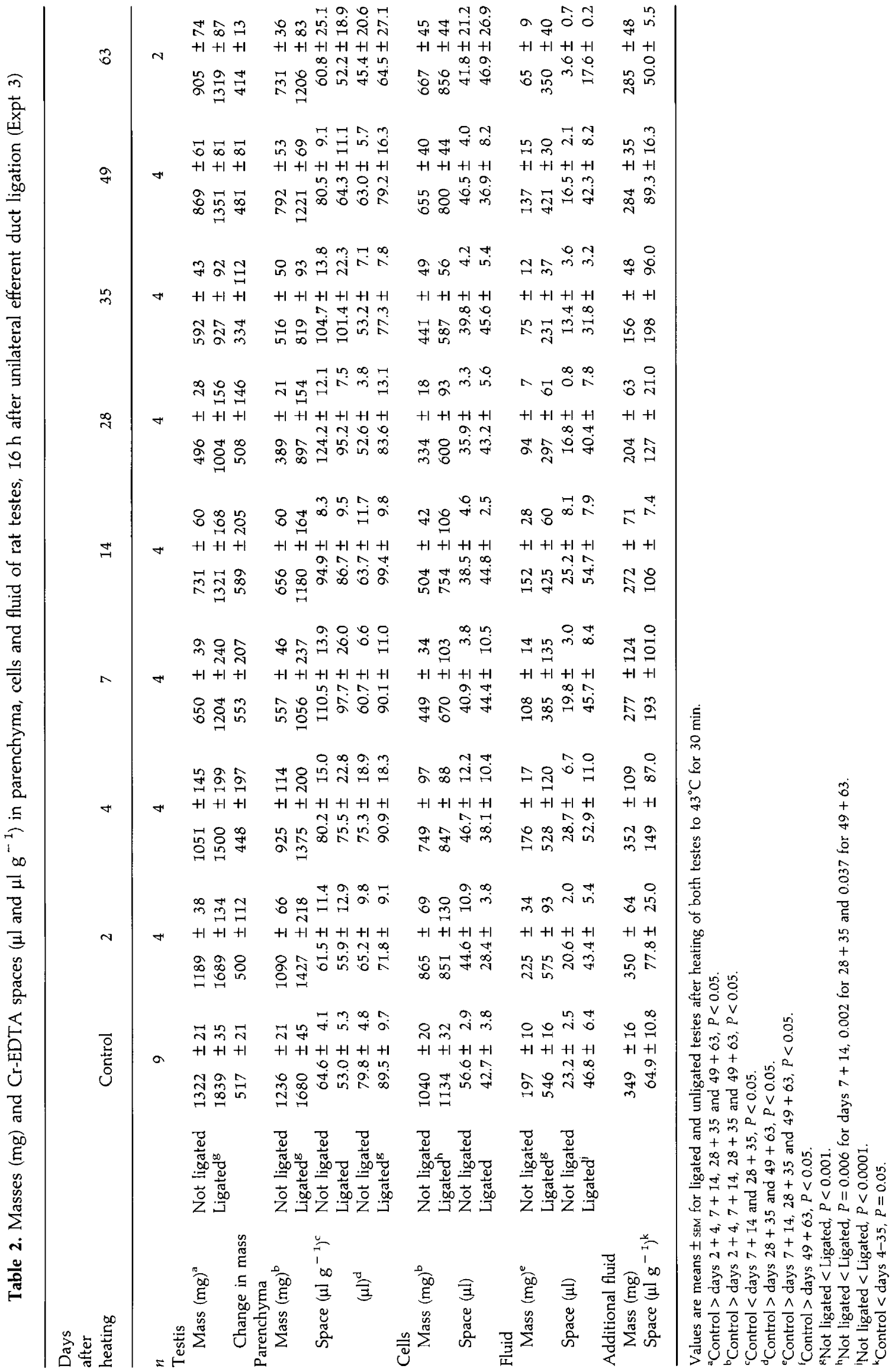




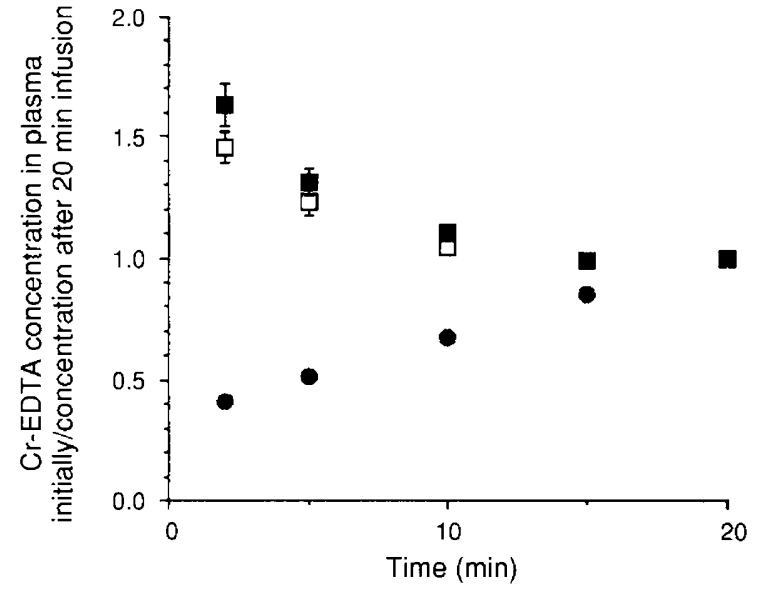

Fig. 1. The concentration of Cr-EDTA in the plasma of (-17 rats infused intravenously at a constant rate following a priming injection or in 24 rats $(\square)$ control rats and ( $\square$ ) for rats whose testes had been heated to $43^{\circ} \mathrm{C}$ for $30 \mathrm{~min}$ at various times previously) which were infused intravenously at an exponentially decreasing rate following a priming dose infused over $20 \mathrm{~s}$. Values are means \pm SEM. Where no error bar is shown it is within the symbol.

time after heating. The Cr-EDTA space in microlitres in the cell fraction was not different between ligated and unligated testes, nor was it affected by the time after heating. However, the fluid space was significantly greater $(P<0.0001, \mathrm{~F}=59.94)$ in the ligated testes, and decreased significantly after heating $(P=0.008, F=3.735$ ), particularly from 28 days (Table 2$)$. Both cell fraction and fluid spaces $\left(\mu \mathrm{g} \mathrm{g}^{-1}\right)$ increased after heating (data not shown), largely as a result of decreases in the masses of the samples. The $\mathrm{Cr}-\mathrm{EDTA}$ space in the capsule in this experiment was about $400 \mu \mathrm{g} \mathrm{g}^{-1}$, and again was unaffected by any of the treatments (data not shown).

The $\mathrm{Cr}$-EDTA concentration in the additional seminiferous tubular fluid was about $6 \%$ of plasma concentrations in the control group, and there was an increase after heating (data pooled for days $0+2,4+7+14+28+35$ and $49+63$, $P=0.05, F=3.216$ by ANOVA), although the variability of this parameter made interpretation somewhat uncertain. Fluid secretion by the testis, whether measured by the increment in testis mass or in fluid mass after ligation of the efferent ducts, was not consistently affected by time after heating.

The concentration of $\mathrm{Cr}$-EDTA in plasma from the posterior vena cava was initially higher than at the end of the $20 \mathrm{~min}$ infusion, but fell rapidly in the early stages, so that from about 10 min onwards, it was virtually constant (Fig. 1).

\section{Experiment 4}

As in the previous experiments, the masses of testes and parenchyma fell after heating the testes, although the decrease was not as great (Table 3). The Cr-EDTA space $\left(\mu \mathrm{g}^{-1}\right)$ in the testis parenchyma was greater in the heated than in the control rats from day 14 after heating onwards, but when expressed in absolute volumes $(\mu \mathrm{l})$, the heated testis showed a significantly smaller volume of distribution for the marker. The volume of the interstitial tissue, assessed by morphometry, also increased after heating, so that the ratio of the chromium space to the interstitial volume remained unchanged.

\section{Discussion}

The results in this paper are relevant to two questions: whether the effectiveness of the blood testis barrier is changed as spermatogenesis becomes deranged following a single exposure of the testes to heat, and to the more general problem of methods for assessing quantitatively the function of the barrier. The differences in the composition of rete testis fluid and seminiferous tubule fluid on the one hand and testicular lymph, interstitial fluid and blood plasma on the other, maintained by the barrier (particularly in relation to those small, water-soluble molecules like inositol, glucose and ions) would be expected to disappear if the barrier had been disrupted. However, it is not known how these differences in concentration would change as the functioning of the barrier is reduced. Studies on the rate of penetration of various markers from blood plasma into rete testis or seminiferous tubule fluid require the collection of testicular fluids over a period of time, with either previous surgical preparation of the animal or anaesthesia. Structurally, the barrier has been located at the specialized junctions between pairs of Sertoli cells, with some contribution from the peritubular cells in some species, and possibly some from the endothelium of the blood vessels in the testis (see Setchell, 1986, 1990; Setchell et al. 1994 for full discussion of this point). A number of studies have relied on the penetration of electron opaque markers into the seminiferous tubules, as determined by electron microscope examination of fixed and sectioned testes, but this approach is difficult to make quantitative, or indeed to extrapolate to the whole organ from the small part of the testis that can practically be examined (see Ploen and Setchell, 1992).

The technique described here depends on the fact that a small water-soluble marker like $\mathrm{Cr}$-EDTA is virtually excluded from rete testis and seminiferous tubule fluid in normal testes, that is, from the lumina of the seminiferous tubules. Previous evidence showing this in rams (Setchell et al., 1969) has now been substantiated for rete testis fluid in rats. If the fluid trapped in the testis following efferent duct ligation is accepted to be equivalent to seminiferous tubule fluid, then we have now produced evidence that $\mathrm{Cr}$-EDTA is also excluded from the tubules. The penetration of the marker into rete testis fluid (about $2 \%$ of plasma concentrations) appears to be slightly, but significantly, less, than into seminiferous tubule fluids (about $5 \%$ of plasma values), which is the reverse of what would be expected, given other evidence that the rete is more permeable than the tubular wall (Johnson, 1970; Setchell et al., 1978). The concentrations of potassium found here in rete testis fluid are similar to that reported in earlier experiments (Setchell et al., 1994). Studies by Howards et al. (1976) have shown that inulin, a marker with similar properties to $\mathrm{Cr}$-EDTA, appears in the seminiferous tubule fluid collected by micropuncture at concentrations also about $5 \%$ of those in blood plasma, a value very similar to our result with $\mathrm{Cr}-\mathrm{EDTA}$, and this figure remains unchanged between about $2 \mathrm{~h}$ and $22 \mathrm{~h}$ after injection of the marker. This equilibrium value is presumably determined by the balance between rate of entry of the marker and the rate of 


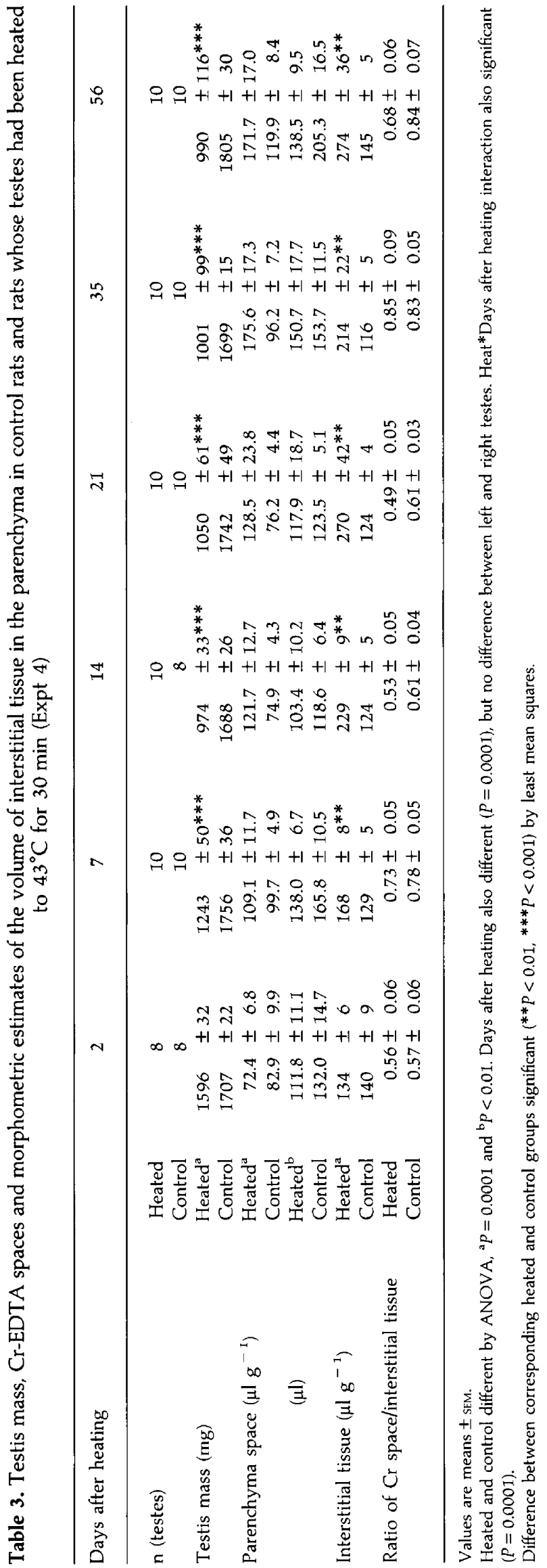


fluid secretion by the cells inside the barrier. Other studies have shown that the volumes of distribution of a number of other extracellular fluid markers, such as inulin and sucrose, were equivalent, or even slightly less, in the whole, ligated testis than in the unligated testis (Setchell, 1974), again suggesting that these markers did not penetrate into the fluid trapped in the tubular lumen. These findings have now been confirmed for the testicular parenchyma using Cr-EDTA and albumin as extracellular fluid markers. The present values for their volume of distribution in the parenchyma are less than earlier estimates of these two parameters for the whole testis; the earlier estimates are likely to have been too large, since the capsule seems to accumulate a disproportionate amount of marker, especially when this is injected i.p. (see also Setchell et al., 1988), and because most of the earlier estimates used the final plasma concentration of albumin without taking into account the fact that the concentration fell substantially between the time of injection and sampling. This would be particularly important with a marker like albumin which requires a fairly long time to reach equilibrium between plasma and tissue (see Setchell, 1990). For Cr-EDTA, the latter error is likely to be less significant. With the injection schedules used here, the mean: final ratios of plasma concentrations were much closer to $I$, and furthermore, this marker penetrates much more quickly than albumin from blood plasma into the interstitial fluid (Setchell and Sharpe, 1981). In the unligated testes, the values for spaces obtained after 10 and $20 \mathrm{~min}$ were comparable, suggesting that equilibrium had been reached after infusion for $10 \mathrm{~min}$. However, the values for the testes whose efferent ducts had been ligated $20 \mathrm{~h}$ earlier were still increasing between 10 and $20 \mathrm{~min}$, suggesting that in these testes, a longer period of infusion was necessary, for reasons that are still obscure. In addition, there were no significant arteriovenous differences across the testes for the marker at either 10 or $20 \mathrm{~min}$, suggesting that the tissue was no longer taking up marker at those times. We have no explanation for the apparently higher albumin concentrations in testicular venous blood from the ligated testes.

In the present experiments, the parenchyma was separated into cell and fluid fractions, as in the previous study (Setchell et al., 1976). This technique would be expected to disperse the tissue without much damage to individual cells, and examination of the dispersate, using a phase contrast microscope, confirms that most of the cells are in clusters, and appear to be intact. However, the supernatant fluid, even after centrifugation at high speed, remained opalescent, suggesting that some cell damage had occurred. In control testes, the mass of the cell fraction was similar in the ligated and unligated testes, as demonstrated by Setchell et al. (1976). The volume of fluid from the unligated testis was between 150 and $200 \mu \mathrm{g} \mathrm{g}^{-1}$; this is presumably made up by luminal fluid, for which morphometric estimates range from 110 to $190 \mu \mathrm{g} \mathrm{g}^{-1}$ (Roosen-Runge, 1955; Setchell, 1970; Setchell et al., 1988) and extracellular interstitial fluid. About $40 \mu \mathrm{lg}^{-1}$ of the latter fluid can be collected from testes post mortem (Sharpe and Cooper, 1983; Turner et al., 1984), a value somewhat less than our present estimate of about $70 \mu \mathrm{g} \mathrm{g}^{-1}$ for Cr-EDTA and I-albumin spaces in the parenchyma. Morphometric estimates of the interstitial tissue of rat testes (Mori and Christensen, 1980; Mendis-Handagama et al., 1987; Setchell et al., 1988 and the present results) suggest that this comprises about $100 \mu \mathrm{g} \mathrm{g}^{-1}$ of the testis, and of this, about $8 \mu \mathrm{g}^{-1}$ is fluid in the lumina of blood vessels (Mendis-Handagama et al., 1987), (assuming a haematocrit of $33 \%$ ) and a further $40 \mu \mathrm{g} \mathrm{g}^{-1}$ is fluid in the lymphatic spaces, which would not include fluid outside the vessels, but between the cells.

The luminal volume was greater in the ligated testis (about $32 \%$ of testis mass) and the interstitial tissue was somewhat compressed, to about $10 \%$. The Cr-EDTA and albumin spaces in the parenchyma were reduced to 50 and $43 \mu \mathrm{l} \mathrm{g}^{-1}$, respectively (see also Setchell, 1970; Tao, 1993). Therefore, the fluid from the ligated testis (about $300 \mu \mathrm{lg}^{-1}$, Setchell et al, 1976 and the present results) would contain a higher proportion of luminal fluid. We did not expect to find that the Cr-EDTA and albumin spaces in the cell fraction would be less in the ligated testis, or that the spaces in the fluid fraction would be greater. We have no explanation for this result, and it does cast some doubt on the validity of the difference technique for estimation of the composition of tubular fluid. However, there is evidence that the composition of the additional seminiferous tubular fluid, obtained by the difference technique, as used in these experiments, is very similar to that of seminiferous tubular fluid obtained by micropuncture (Setchell et al., 1978), with respect to ionic composition and the concentrations of inositol and protein. In addition, using a modification of our technique, involving rinsing of the tubules to remove the extracellular fluid before dispersing the tubular cells and centrifuging the cell dispersion, Turner et al. (1984) found that the androgen and androgen-binding protein concentration in the fluid obtained was very similar to that sampled by micropuncture. We, therefore, have some confidence in the results which suggest that the concentration of Cr-EDTA in the additional seminiferous tubular fluid is higher in the testes regressing after heat. However, in view of the problems outlined above, it was considered that an additional technique should also be used.

The additional technique relies on the ratio between the Cr-EDTA space and a morphometric evaluation of the interstitial tissue volume in the same testis. For this technique, it is important to obtain a true value for the Cr-EDTA space, and, therefore, an attempt was made to achieve a steady concentration of marker in the plasma and the mean plasma value was used in the calculations. During the disruption of spermatogenesis following heating of the testis, this technique indicated that there was no diminution in the effectiveness of the barrier; in fact, the ratios were slightly, although not significantly, less in the heated testes. It would, therefore, appear that although spermatogenesis is profoundly affected, the barrier remains functional, and this presumably permits spermatogenesis to be re-established promptly. The present studies do not tell us anything about the function of the barrier during heating, as studied by Main and Waites (1977).

One function of the barrier is to allow fluid secretion to proceed, and a surprising and inexplicable difference between the present results and earlier studies (Setchell and Waites, 1972; Jegou et al., 1984, Au et al., 1987) was our failure to observe any consistent decreases in fluid secretion by the heated testes. Previous studies in rams (Setchell et al., 1971) reported that fluid secretion was unchanged after heating the testes, even though sperm concentrations in rete testis fluid 
were profoundly depressed. We have no explanation for this difference, except that in the experiments of both Jegou et al. (1984) and Au et al. (1987), there were some groups of animals that showed reductions in testis mass, without any change in fluid secretion, whereas in others, both testis mass and fluid secretion were reduced. Testis mass does not appear to be a factor, although in another set of experiments (Setchell and Waites, 1972), the reduction in fluid secretion was directly related to the reduction in testis mass.

The increase in the mass of the cell fraction in the heated testes, following efferent duct ligation, may indicate that cells are being lost from the epithelium following heating, and being carried into the epididymis in appreciable quantities, much greater than the mass of the spermatozoa that are being released normally and trapped by the ligature, but do not have any appreciable effect on the mass of the cell fraction.

In summary, we consider that the method described and used here is a valid and novel way of assessing quantitatively the function of the blood-testis barrier. This method has shown that during the period of spermatogenic damage following a single exposure of the testes to heat, the blood-testis barrier is either unaffected, or shows only minor changes. It remains to be seen whether the barrier to $\mathrm{Cr}-\mathrm{EDTA}$ changes during the actual period of heating.

We are grateful to $\mathrm{S}$. Sowerbutts for his assistance with Experiments 2 and 3.

\section{References}

Au CL, Robertson DM and de Kretser DM (1987) Changes in testicular inhibin after a single episode of heating of rat testes Endocrinology 120 973-977

Chowdhury AK and Steinberger E (1964) A quantitative study of the effect of heat on the germinal epithelium of the rat testis American journal of Anatomy $115509-524$

Chowdhury AK and Steinberger E (1970) Early changes in the germinal epithelium of rat testes following exposure to heat Journal of Reproduction and Fertility 22 205-212

Collins P and Lacy D (1969) Studies on the structure and function of the mammalian testis II. Cytological and histochemical observations on the testis of the rat after a single exposure of heat applied for different lengths of time Proceedings of the Royal Society of London Series B 172 17-38

Daniel PM, Donaldson J and Pratt OE (1975) A method for injecting substances into the circulation to reach rapidly and to maintain a steady level Medical and Biological Engineering $13214-227$

Galil KAA and Setchell BP (1988) Effects of local heating of the testis on testicular blood flow and testosterone secretion in the rat International Journal of Andrology 11 73-85

Howards SS, Jessee SJ and Johnson AL (1976) Micropuncture studies of the blood-seminiferous tubule barrier Biology of Reproduction 14 264-269

Jegou B, Laws AO and de Kretser DM (1984) Changes in testicular function induced by short-term exposure of the rat testis to heat: further evidence for interaction of germ cells, Sertoli cells and Leydig cells International Journal of Andrology 7 244-257

Johnson MH (1970) Changes in the blood-testis barrier of the guinea-pig in relation to histological damage following iso-immunization with testis journal of Reproduction and Fertility 22 119-127

Main SJ and Waites GMH (1977) The blood-testis barrier and temperafure damage to the testis of the rat journal of Reproduction and Fertility 51 $439-450$
Mendis-Handagama, SMLC, Risbridger GP and de Kretser DM (1987) Morphometric analysis of the components of the neonatal and adult rat testis interstitium International Journal of Andrology 10 523-534

Mori $\mathrm{H}$ and Christensen AK (1980) Morphometric analysis of Leydig cells in the normal rat testis Journal of Cell Biology 84 340-354

Pelletier RM (1986) Cyclic formation and decay of the blood-testis barrier in the mink (Mustela vison) American Journal of Anatomy 175 91-117

Pelletier RM (1988) Cyclic modulation of Sertoli cell junctional complexes in a seasonal breeder: the mink (Mustela vison) American Journal of Anatomy 183 $68-102$

Ploen L and Setchell BP (1992) Blood-testis barriers revisited. A homage to Lennart Nicander International Journal of Andrology 15 1-4

Pratt OE (1974) An electronically controlled syringe drive for giving an injection at a variable rate according to a preset programme Joumal of Physiology 237 5P-6P

Roosen-Runge EC (1955) Quantitative studies on spermatogenesis in the albino rat. III. Volume changes in the cells of the seminiferous tubules Anatomical Record 123 385-398

Setchell BP (1970) The secretion of fluid by the testes of rats, rams and goats, with some observations on the effect of age, cryptorchidism and hypophysectomy Journal of Reproduction and Fertility 23 79-85

Setchell BP (1974) The entry of substances into the seminiferous tubules. In Male Fertility and Sterility Eds RE Mancini and L Martini. Academic Press, New York

Setchell BP (1986) The movement of fluids and substances in the testis Australian Journal of Biological Sciences 39 193-207

Setchell BP (1990) Local control of testicular fluids Reproduction, Fertility and Development 2 291-309

Setchell BP and Main SJ (1975) The blood-testis barrier and steroids Current Topics in Molecular Endocrinology 2 223-233

Setchell BP and Sharpe RM (1981) Effect of injected human chorionic gonadotrophin on capillary permeability, extracellular fluid volume and the flow of lymph in the testes of rats Journal of Endocrinology 91 245-254

Setchell BP and Waites GMH (1972) The effects of local heating of the testis on the flow and composition of rete testis fluid in the rat, with some observations on the effects of age and unilateral castration Journal of Reproduction and Fertility 30 225-233

Setchell BP, Voglmayr JK and Waites GMH (1969) A blood-testis barrier restricting passage from blood into rete testis fluid but not into lymph Journal of Physiology $20073-85$

Setchell BP, Voglmayr JK and Hinks NT (1971) The effect of local heating on the flow and composition of rete testis fluid in the conscious ram Journal of Reproduction and Fertility 24 81-89

Setchell BP, Hinton BT, Jacks F and Davies RV (1976) The restricted penetration of iodinated rat FSH and $\mathrm{LH}$ into the seminiferous tubules of the rat testis Molecular and Cellular Endocrinology 6 59-69

Setchell BP, Davies RV, Gladwell RT, Hinton BT, Main SJ, Pilsworth LM and Waites GMH (1978) The movement of fluid in the seminiferous tubules and rete testis Annales de Biologie Animale, Biochemie et Biophysique 18 623-632

Setchell BP, Pollanen PP and Zupp JL (1988) Development of the blood-testis barrier and changes in vascular permeability at puberty in rats International Journal of Andrology 11 225-233

Setchell BP, Maddocks S and Brooks DE (1994) Anatomy, vasculature, innervation and fluids of the male reproductive tract. In The Physiology of Reproduction (2nd Edn) pp 1063-1175 Eds E Knobil and JD Neill. Raven Press, New York

Sharpe RM and Cooper I (1983) Testicular interstitial fluid as a monitor for changes in the intratesticular environment in the rat Journal of Reproduction and Fertility $69125-135$

Steinberger E and Dixon WJ (1959) Some observations on the effect of heat on the testicular germinal epithelium Fertility and Sterility 10 578-595

Tao L (1993) The Blood-testis Barrier and Blood Vessel Permeability in Rat Testis. PhD Thesis, University of Adelaide

Turner TT, Jones CE, Howards SS, Ewing LL, Zegeye B and Gunsalus GL (1984) On the androgen microenvironment of maturing spermatozoa Endocrinology 115 1925-1932 